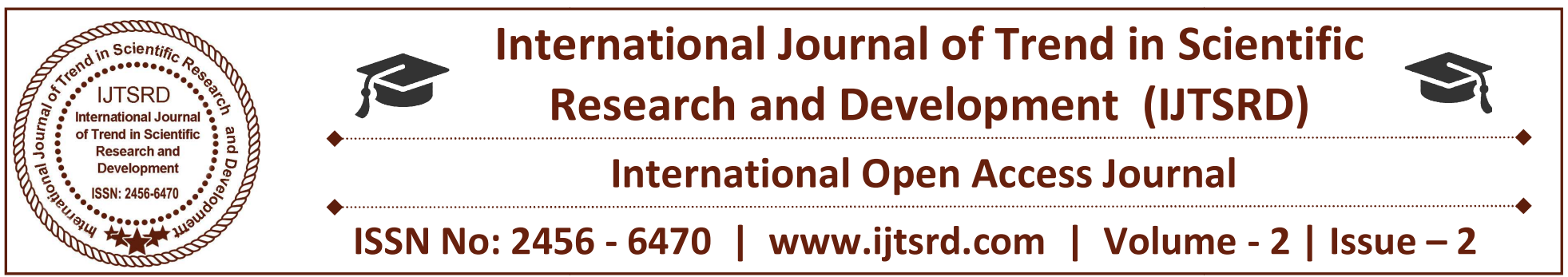

\title{
Structural Marketing Pedagogy and Market Demarcation- Substituting Demographic Analysis
}

\author{
Dhruv Sabharwal \\ Assistant Professor, Amity University, \\ Madhya Pradesh, India
}

\begin{abstract}
The reason for the paper is to introduce an auxiliary investigation of statistical surveying and target showcase division strategies in Place Marketing execution. The paper concentrates on city's inner and outside condition in smaller scale macroeconomical level, attempting to set up an extensive variety of essential inquiries concerning the arranging and the fruitful execution of Place Marketing The initial segment of the paper investigations Place Marketing as a vital system. The second and the third parts look at the part of statistical surveying and target showcase division in the Place Marketing process. The fourth part shows an auxiliary examination, by putting statistical surveying and target showcase division methodology into city's inward and outside condition, in an assortment of ranges of investigation. Moreover, some critical inquiries identified with every range and condition of examination are talked about. The article underpins that this structure is portrayed by adaptability since it can be utilized as a part of more particular research fields, for example, tourism, culture, development, business exercises, relaxation and diversion and so forth.
\end{abstract}

Keywords: Advertising, Statistical Surveying, Target Showcase Division

\section{Place Marketing System}

Place/city showcasing constitutes a standout amongst the most fascinating territories of research the most recent twenty years, since numerous urban areas all around and particularly in Europe utilize advancement arrangements keeping in mind the end goal to help their pictures and end up noticeably aggressive among different urban communities (Ashworth and Voogd, 1990; Kotler et al, 1993; 1999; Duffy, 1995; Ward, 1998; Bramwell $\kappa \alpha 1$

Rawding, 1996; Selby and Morgan, 1996; Hope and Klemm, 2001, Avraham 2000, 2004; Urban, 2002). Bramwell (1998) underpins that the showcasing of place items ought to be founded on the general vision and the arrangement objectives for the place, what impacts which city items, and limited time pictures are focused at which clients. Also Usyal et al., (2000) contended that for a place to wind up plainly a perceived goal shows a troublesome advertising challenge, since to keep up a positive picture in the psyches of guests might be significantly more troublesome on the grounds that option and focused goals are continually pushing the cutoff points of market rivalry.

Place Marketing supporters, who start with the customary hypothesis of Marketing "4ps" (item, value, put, advancement) [Kotler, 1986], distinguish neighborhood monetary improvement and city intensity as objectives, ascribing the idea of "item" or "great" to the city itself, and perceiving the advancement techniques as a standout amongst the most vital components of urban areas aggressiveness, knowing while city picture advancement constitutes something more confused and multi-dimensional. They miss the mark concerning the examination of urban areas' inner and outer condition, the defended recognizable proof of the potential target showcases, 
the improvement of specific methodologies for potential target markets fulfillment and furthermore the introduction of a particular philosophy of Place Marketing viability estimation (Metaxas and Petrakos, 2004). This very point is particularly essential since monetary geographers basically, (Cheshire and Gordon, 1998; Cheshire and Magrini 1999, 2001; Rodriguez-Pose and Arbix, 2001) discuss the 'Waste Strategies', wonder, that is the systems for the fascination of potential target markets, which created and performed with no sort of assessment and subsequently they don't produce any benefit on nearby and additionally on territorial level.

\section{Market Research}

Statistical surveying constitutes an essential piece of a powerful Place Marketing Plan execution (van Limburg 1998; Jansen-Verbeke and van Rekom 1996, Garrod et al, 2002). The greater part of studies concentrate on tourism and social improvement of urban communities and districts, utilizing essential looks into and econometric - quantitative examination. These inquires about concern the examination of tourism drifts all around, the investigation of travelers' conduct and their specific attributes, the reviewing of qualities and shortcomings of urban areas so as to end up noticeably focused in global tourism and social market and so forth. Garrod et al (2002), presents the discoveries of a postal study of the greater part of Scotland's 510 paid affirmation attractions in 1999. The overview investigated impression of the range and seriousness of guest impacts, relating these effects to elements, for example, fascination sort, affirmation costs, guest numbers and possession status. Moreover, Lim and McAleer, (2001) concentrate their examination on estimating quarterly global vacationer entries in Australia, utilizing exponential smoothing techniques for the period 1998(1)-2000(1), while Balaz and Mitsutake, (1998) utilizing showcasing reviews and factual information from national and worldwide sources, research the developing examples of tourism trade amongst Japan and progress nations of Central Europe, keeping in mind the end goal to clarify the traveler streams, the visitor conduct and the intentions in going by this area. Likewise Deffner and Metaxas (2003) and Metaxas and Deffner (2004), explore the part of exhibition hall advertising and administration on put engaging quality, utilizing statistical surveying investigation out in the open galleries of Greece, while Uysal et al, (2000) and Chen (2003), inspected the aggressive position of Virginia with eight other eastern US states, by utilizing showcasing overviews to Virginia inhabitants and family units, keeping in mind the end goal to comprehend the qualities and shortcomings, to recognize the particular attributes and to review those open door zones that would empower Virginia to win an offer from focused zones.

\section{Target market division}

Target showcase division is identified with the emphasis on particular target-markets and particularly on traveler (Chen, 2003; Kastenholtz et al, 1999). A few investigations utilized division examination keeping in mind the end goal to look at the most productive portions in existing target bunches that best amplify an incentive to the goal. Carmichael's investigation (2002), investigates the spatial effect of the Barnes Exhibit (Ontario, Toronto) in a division examination of 'away' Barnes Exhibit guests, by utilizing gravity models to depict the separation rot impact, while Mykletun et al, (2001), utilized different strategic relapse examination and autonomous factors, for example, the nationality, family wage, instruction age, travel party organization and outing reason, with a specific end goal to distinguish the goal's most significant guest fragments and additionally the goal's relative capacity to fulfill each of them, in Bornholm island of Baltics.

Target showcase division happens on nearby, local, national and global level. As indicated by Short and Kim (1998), the essential target markets concern remote endeavors, voyagers, future occupants, while Lecomte and Gollain, (1992), discussing Paris and London, distinguished as target markets, culture, tourism, the high innovation focuses, the worldwide bank and money related organizations. Besides, Kotler et al., (1999:33), bolster that the most huge target markets are guests, occupants and working populace, ventures and enterprises and the remote markets

In light of Ashworth and Voogd's arrangement (1990:49) there are three fundamental division techniques: a) concentrated methodology, that spotlights on one particular target showcase. The most vital piece of this usage concerns the distinguishing proof of the specific qualities of the chose target showcase, all together for the gave city's picture to meet the point of view picture that this objective market has for the chosen urban communities, 
b) separated methodology, by picking different target showcases yet in addition an alternate system of continuing each of them and c) undifferentiated technique, when focus on business sectors' treatment is the same for all, offering a steady procedure for each of them independently.

1. Putting Market Research and Target Market Segmentation in City's inward and outer condition

\subsection{Market research in city's inner and outer condition}

Statistical surveying in urban areas inside and outer condition concerns the investigation of different ranges that are perceived as huge before the arranging and the execution of a Place Marketing Plan. These zones have a typical base, yet their investigation is unique, since in interior condition the examination concerns the micro economical level, while the investigation of the outside condition concerns the macro economical measurement. The territories of examination are (table 1): a) Trends and demeanors in the city: This investigation concerns the recognizable proof and the assessment of patterns and states of mind on issues, for example, the tourism, the way of life, recreation exercises, the innovation and advancement, the character and the level of business activities, the qualities and the conventions of the place and so on. The primary point is the examination of the requests, the requirements and the view of the current city's objective markets and its district, also. These objective markets are: inhabitants, undertakings, open monetary associations (i.e. assemblies of trade and industry), non benefit associations, preparing focuses, innovative establishments, colleges, social, tourism and ecological affiliations and so on., b) Local strengths, organizations advancement and designation of parts and duties. This second territory of examination concentrates on the part and the commitment of urban areas powers (on-screen characters) to the improvement and the aggressiveness of urban communities (regions). Moreover, it's been analyzed the level and the character of the associations between urban areas on-screen characters so as to advance and bolster the picture of the urban areas viably, c) Identification of the potential target showcases: The recognizable proof of the objective markets depends on the reviewing of urban areas particular qualities, the making of unmistakable merchandise applying to the objective markets, in nearby and provincial urban communities condition, d) Residents and other city's objective markets: Identification of those objective markets that are the most beneficial for the city, the sort of correspondence and participation forms with the inhabitants and the other target markets of the city, e) Competitors in territorial level: This region concerns the investigation of rivals in local level, since different urban areas

An exceptionally trademark illustration is that of Larissa-Volos dipole in Thessaly locale of Greece, where two urban areas with various upper hands contend each other (and coordinate likewise) in a similar district (Thessaly district), so as to overwhelm one upon alternate (Metaxas T., and Kallioras D, 2003) and f) Promotion techniques: this last region of investigation concerns the arranging, the assessment and the execution of procedures, strategies and option situations per target showcase considering the particularities that they display.

Table 1 shows the territories of investigation of statistical surveying strategy in the interior and outer condition of a city. Every zone is joined by some vital inquiries, which make an auxiliary investigation out of statistical surveying arranging and execution.

\subsection{Target market division in city's inner and outside condition}

On account of target showcase division there are likewise specific territories of examination and investigation, concerning city's condition. All the more especially these territories concern the accompanying a) Segmentation of patterns and states of mind as they got from statistical surveying, arranging the necessities and the view of the objective markets (the current request), yet in addition the levels of fulfilling these requirements from city's condition (the current supply), b) Segmentation of the procedures, strategies and option situations: This investigation concerns the assessment and the last determination of vital tomahawks of activities execution, characterizing the great methodologies, the strategies and the presence of adaptable option situations lastly the assessment of particular systems for each activity advancement per division of target advertise, c) Segmentation criteria: The recognizable proof of the primary division criteria incorporates three major classes of examination:

Segmentation of occupants' attributes: the inhabitants constitute the real potential target 
market of urban communities condition. The compelling advancement and the arrangement of city's "products" require the division of their attributes, since in statistical surveying process, they're patterns and their buying conducts have been recognized.

$>$ Segmentation of city's qualities: this procedure concerns the classification of financial, urban, innovative, ecological, business, social and recreation offices that every city has and offers to the potential target markets. This stage surmises the recognizable proof of a city's unmistakable qualities, the legitimization of the chose target markets and the division in light of their particularities and their acquiring conduct.

$>$ Segmentation of city's on-screen characters: It concerns, the division of parts and activities that a city's on-screen characters take up in the city's condition (who is doing what, how and when), The level of their specialization (level of their adequacy), the methods for associations amongst them and with the potential target markets.

d) Segmentation of rivalry regions: For this situation division concerns the recognizable proof of the piece of the pie that the city holds towards its rivals, both on a general level and as per its particular qualities, so as to enhance its position among other contender urban areas.

The regions of investigation of target showcase division strategy in the inner and outer condition of a city. Every range is joined by some essential inquiries, which make an auxiliary investigation out of target showcase division arranging and execution.

\section{Conclusions}

The article concentrates on the examination of statistical surveying and target advertise division techniques, critical parts of Place Marketing adequacy. The two methodology can design and performed in city's inward and outside condition following the basic model that the paper proposed. The last gave great of the city is its picture. Along these lines, we can't build up a key place-advertising design, so as to advance this picture effectively, without noting first some fundamental inquiries as to the examining examination of the circumstance in the inward and the outer city's condition (a basic investigation). Each of these inquiries constitutes a guide-instrument of breaking down every zone viably. The adequacy of every zone examination relies upon city's organizers and advertisers' capacity to give the suitable answers each time

Moreover, the achievement of target advertises division surmises the quality and the level of adequacy of Market investigate (agent subjective and quantitative examination of the present circumstance). In this way, we could bolster that statistical surveying and market division, happen after SWOT and PEST investigation and before the place/city showcasing plan usage.

At long last, the article bolsters that the proposed auxiliary examination is portrayed by adaptability since it can be utilized as a part of more particular research fields, for example, tourism, culture, advancement, business exercises, relaxation and entertainment and so on.

\section{Table 1: Inside Furthermore outer city nature's domain (Local and Regional). Statistical surveying.}

\section{Regions for examination replies to inquiries (Internal) replies to inquiries (External).}

Patterns and Attitudes in the city:. Tourism, advancement What's more Technology, recreation What's more Recreation, traditions conduct Also traditions, business exercises What's more entrepreneurship, Planning, caliber of an aggregation and so forth

Fundamental questions:. - the thing that is those degree of the neighborhood Also territorial patterns Also attitudes, which impact the locality's (city's) improvemen policies?. how simple may be it for those area on take after these patterns or on embrace these attitudes?. - can those area bring those suitable improvement approaches should fulfill the inward market requests effectively?.
Fundamental questions:. - What may be those level of the european and worldwide patterns and attitudes which impact the locality's (city's) advancement policies?. - how simple will be it to the area should take after these patterns or on embrace these attitudes?. - does the area bring those suitable improvement approaches on fulfill the business requests effectively?. 
Performing artists commitment What's more partnerships between: government funded neighborhood Furthermore territorial Authorities, Enterprises, business incubators, Europe, hypothetical orders had more distinction than difficult work, and speculative chemistry was What's more Scrutinize centers, innovative and improvement centers, advancement agencies, consultancies, culture, tourism and Ecological organizations, citizens, guests.

Essential questions: what would those fitting outside accomplices that the city need on a chance to be co- operated?. - what will be the fields for these co- operations?. - the thing that will be those part and the level of commitment about neighborhood government toward oneself of the improvement for these cooperations?. - the thing that will be those relied upon benefits of these co-operations?. - how not difficult will be to those area with arrange and create these co-operations?

\section{Fundamental questions}

Who will be on accuse of the improvemen about co-operations for the outer partners?. Who will circulate the parts and the responsibilities the middle of the helping actors?. - Who will assess those caliber and the level about viability from claiming these cooperations?. - the thing that will be precisely those mission and the degree about every outside co- operation?.

\section{Fundamental questions}

- Can the city bring the ability to arrangement What's more will perform vital promotional movements On co-operation for different urban areas or associations done abroad?. - the thing that will be the plan, the situations and the character from claiming every cooperation?. - the thing that will make the 'actions promotional package' to every co-
Fundamental questions:. - how is the nearby investment improvement associated with urban policies? - the thing that will be the part of the private division (enterprises) with nearby advancement achievement?. - what will be the part and the level for force of nearby government toward oneself should neighborhood improvement achievement?. - the thing that is those part and the level for commitment for Universities, benefits of the business incubators Also improvement centers? - how simple may be it for those area on assess these patterns Furthermore to receive effective components from claiming improvemen movements and promotional activities?.

Parts and responsibilities for every performer. Sectors: planning, research, venture management, controlling, organising, programming, assessment of reaction procedure, budgetary management, human assets management, choice makers and so forth.

Essential questions:- - Who will be on charge of the vital arranging procedure? - Who will circulate those parts and the responsibilities between those helping actors? - Who will make those choice maker/makers? - Who will execute the spot / city promoting want

Strategies, strategies Furthermore elective situations nonexclusive 1 improvement strategies, particular methodologies for every sector, key plans, promotional actions, waste methodologies.

\section{Fundamental questions}

$\therefore$-Does the city need those limit with arrangement Also to perform vital promotional activities for co-operation for alternate urban communities clinched alongside fringe region. -Are these promotional Furthermore improvement activities related with those locality's dream Also goals?. Are these promotional and improvemen activities related with the periphery's development, also?. - what will be those extra worth on the locality's and the periphery's improvemen concerning outer vital activities received by those locality?.

\section{Essential questions}

The thing that would those fundamental rival ranges those area is faced with?. - can the area recognizing its similar favorable circumstances so as with face its competitors?. Might the city make a similar focal point in the event that it doesn't bring any?.

Essential questions:- - the thing that need aid the primary rival zones those area is faced with?. - does the area 
operation?. - what may be those extra worth on the locality's and the periphery's development?. recognizing its similar preferences so as will face its competitors?. - Might the city make An similar focal point in the event that it doesn't have any?.

Table 2

Interior Furthermore outside city surroundings (Local-Regional Furthermore national - International).

Showcase division. Zones for dissection replies to inquiries.

Replies to inquiries (External).

(Internal).

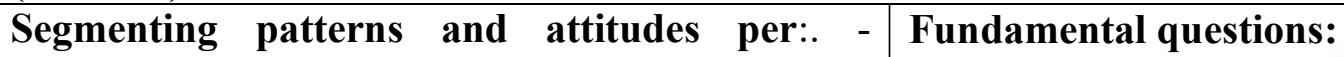

Development Furthermore promotional territory (culture, tourism, earth and so forth throughout this way, observing and stock arrangement of all instrumentation may be enha. ). -Potential target businesses favors (the existing demand). - the level about patterns What's more attitudes fulfillment (the existing supply).

Fundamental questions: - does the area need the required ability on face the possibility demand?. can those area need the required supply should pull in the chosen possibility focus markets?.

Segmenting Strategies, strategies Also elective situations for every area situation / study:. 2 principle methodologies (excellent) for every division What's more movement. - elective situations for every segment and movement. Tactics for every division Furthermore movement. -Specialized strategies for every segment Also movement

Essential questions:- - how are the chose methodologies joined with the approach of the chose focus markets?. - how need aid those chosen methodologies joined with those advancement from claiming city's picture globally? - how would the chosen methodologies interfaced for those chosen gainful focus markets?. - under the thing that states those division for methodologies camwood be successful?.

Fundamental questions:. - what will a chance to be the division criteria In the area chooses will approach particular global target businesses (i. E. FDI, elective sorts about tourism, individuals with exceptional needs, players etc). - the thing that will a chance to be the assessment and sentiment processes?. - how those area will utilize the majority of the data so as will raise a powerful advancement one bundle advertising to these markets?.
. - can the area need the obliged ability will fulfill the possibility request from claiming remote markets?. - can the area need the required ability with change or to reconstruct its picture in place should pull in the remote target markets? - how not difficult will be for the city with convert a negative picture (if there may be one) to sure one?.

\section{Fundamental questions}

$\therefore-$ the thing that need aid those principle qualities of these strategies?. - how would those performed methodologies (per Examining area) joined with an area's monetary development? - how are the performed methodologies joined with those territorial area?.- Which about these methodologies would waste strategies?. Which about these methodologies Might a chance to be embraced Eventually Tom's perusing the locality?.

\section{Fundamental questions}

$\therefore$ - what will be the approachability level about infiltration of the chosen focus markets?. - what specific division methodologies does the city must perform in place to fragment these target markets?. - what means, strategies or systems can the city require to utilize so as should perform division transform effectively?. - what are those particular necessities Furthermore desires for each target business sector that the city need to satisfy?.

Fundamental inquiries.

-How the city will utilize the grade information in place to make viable division arrangements (methods)?. -How simple will be for the city choice makers and the organizers with actualize all the division arrangements for every every last one of city's inward focus 


\section{REFRENCES:}

1. CHESHIRE P.C, and MAGRINI S., (2001), Policies for urban growth, local public goods, spillovers and convergence/ divergence: some empirical and methodological answers, ESRC Cities programme

2. DEFFNER A. and METAXAS T., (2003) The interrelationship of urban economic and cultural development: The case of Greek museums, paper presented to the $43^{\text {rd }}$ ERSA Congress Peripheries, centers, and spatial development in the new Europe, University of Jyväskylä, Jyväskylä, Finland

3. DUFFY, H., (1995), Competitive Cities: Succeeding in the Global Economy, London: Spoon

4. GARROD B., FYALL A., and LEASK A., (2002), Scottish visitor attractions: managing visitor impacts, Tourism Management, 23(3):265279

5. HOPE, A.C., and KLEMM, S.M., (2001), Tourism in difficult areas revisited: the case of Bradford, Tourism Management, 22, pp. 35-47

6. JANSEN-VERBEKE, M. and VAN REKOM, J., (1996) Scanning museum visitors, Annals of Tourism Research, vol. 23., no 2., pp. 364-375

7. KASTENHOLTZ, E., DAVIS, D., and PAUL, G., (1999), Segmenting tourism in rural areas: The case of north and central Portugal, Journal of Travel Research, 37(2): 353-363

8. KOTLER P., ASPLUND C., REIN I., and HAIDER H.D., (eds) (1999) Marketing Places Europe. Prentice Hall

9. KOTLER P., REIN I., and HAIDER H.D., (1993) Marketing Places: Attracting Investment, Industry, and Tourism to Cities, Regions and Nations, Free Press N.Y

10. KOTLER P., (1986) Principles of Marketing Prentice Hall, Englewood, Cliffs ( $3^{\text {rd }}$ eds), in ASHWORTH J.G and VOOGD H., 1990 Selling the City, Belhaven Press

11. LECOMTE D and GOLLAIN V., (1992) La position concurrentielle le I'lle de France en Europe, Les Cahiers de I'IAURIF, 100, pp. 9-24

12. LIM C., and MCALEER M., (2001), Forecasting Tourist Arrivals, Annals of Tourism Research, 28(4):965-977

13. METAXAS T., and PETRAKOS G., (2004) Measuring urban competitiveness: from traditional economic factors to promotion policies and strategic planning, [forthcoming in Proceedings of the $2^{\text {nd }}$ International Conference, Enlarged Europe and Regional Inequalities, Technological Education Institute of Epirus] (in Greek)

14. METAXAS T., and KALLIORAS D., (2003) Medium-size economic development and regional competitiveness: the case of Larissa-Volos dipole in Thessaly region of Greece, paper presented to the $9^{\text {th }}$ Regional Studies Association International Conference' Reinventing Regions in a Global Economy' Pisa, 12-15 April

15. METAXAS T., DEFFNER A., (2004) Marketing, management and promotion of city image: defining the role and the contribution of public museums in Greece, [forthcoming in Proceedings of the $2^{\text {nd }}$ International Conference of Museology, University of Aegean]

16. MYKLETUN R.J, CROTTS J.C, and MYKLETUN A., (2001) Positioning an island destination in the peripheral area of the Baltics: a flexible approach to market segmentation, Tourism Management, vol. 22 pp. 493-500

17. RODRIGUEZ-POSE A., and ARBIX G., (2001), Strategies of Waste: bidding wars in the Brazilian automobile sector, International Journal of Urban and Regional Research, 25 (1): 134-155

18. SELBY, M., and MORGAN, J. N., (1996), Reconstructuring place image: A case study of its role in destination market research, Tourism Management, 17 (4), pp. 287-294

19. SHORT R.J and KIM Y-H, (1998), Urban Crises / Urban representations: selling the city in difficult times in T. HALL and P. HUBBARD, (eds) (1998) The Entrepreneurial City,. J. Wiley and Sons.

20. STRATEGIES EUROPE MAGAZINE (2001) No 4., 2001: 38

21. URBAN F., (2002), Small Town, Big Website? Cities and their Representation on the Internet', Cities, vol.19, pp. 49-59

22. UYSAL M., CHEN S.J., and WILLIAMS D., (2000), Increasing state market share through a regional positioning, Tourism Management, 21, pp. $89-96$

23. VAN LIMBURG B., (1998), Research note: City marketing: a multi-attribute approach, Tourism Management, vol. 19, no.5, pp.475-477

24. WARD V.S., (1998), Selling Places: The marketing and promotion of towns and cities 1850-2000', Routledge, London, New York 